\title{
End-of-life perceptions among physicians in intensive care units managed by anesthesiologists in Germany: a survey about structure, current implementation and deficits
}

Manfred Weiss ${ }^{* *}$, Andrej Michalsen ${ }^{2}$, Anke Toenjes ${ }^{1}$, Franz Porzsolt ${ }^{3}$, Thomas Bein $^{4}$, Marc Theisen ${ }^{5}$, Alexander Brinkmann ${ }^{6}$, Heinrich Groesdonk ${ }^{7}$, Christian Putensen ${ }^{8}$, Friedhelm Bach ${ }^{9}$, Dietrich Henzler ${ }^{10}$, On behalf on the Working Group Epidemiology and Ethics of the German Society of Anesthesiology and Intensive Care Medicine (DGAl)

\begin{abstract}
Background: Structural aspects and current practice about end-of-life (EOL) decisions in German intensive care units (ICUs) managed by anesthesiologists are unknown. A survey among intensive care anesthesiologists has been conducted to explore current practice, barriers and opinions on EOL decisions in ICU.

Methods: In November 2015, all members of the German Society of Anesthesiology and Intensive Care Medicine (DGAI) and the Association of German Anesthesiologists (BDA) were asked to participate in an online survey to rate the presence or absence and the importance of 50 items. Answers were grouped into three categories considering implementation and relevance: Category 1 reflects high implementation and high relevance, Category 2 low and low, and Category 3 low and high.

Results: Five-hundred and forty-one anesthesiologists responded. Only four items reached $\geq 90 \%$ agreement as being performed "yes, always" or "mostly", and 29 items were rated "very" or "more important". A profound discrepancy between current practice and attributed importance was revealed. Twenty-eight items attributed to Category 1, six to Category 2 and sixteen to Category 3. Items characterizing the most urgent need for improvement (Category 3) referred to patient outcome data, preparation of health care directives and interdisciplinary discussion, standard operating procedures, implementation of practical instructions and inclusion of nursing staff and families in the process.

Conclusion: The present survey affirms an urgent need for improvement in EOL practice in German ICUs focusing on advanced care planning, distinct aspects of changing goals of care, implementation of standard operating procedures, continuing education and reporting of outcome data.
\end{abstract}

Keywords: Anesthesiologists, Education, Continuing, End-of-life care, Goals, Intensive care units, Palliative care, Patient care planning, Prognosis, Quality of life, Surveys and questionnaires

\footnotetext{
* Correspondence: manfred.weiss@uni-ulm.de

${ }^{1}$ Clinic of Anaesthesiology, University Hospital Medical School,

Alber-Einstein-Allee 23, 89081 Ulm, Germany

Full list of author information is available at the end of the article
} 


\section{Background}

The question of end-of-life (EOL) care has recently reached modern intensive care medicine. Several aspects need to be considered, such as differences in ethnicity, country and medical specialty. An updated summary of published statements on EOL care in the ICU from national societies has currently been presented, highlighting commonalities and differences within and between international regions [1]. Therein, the complexity of EOL care in the ICU within different ethical and cultural environments, particularly relating to withholding and withdrawing life-sustaining treatment while ensuring the alleviation of suffering, has been recognized. Subsequently, the World Federation of Societies of Intensive and Critical Care Medicine has encouraged their member societies to lead the debate and to develop national guidelines and recommendations regarding EOL care in the ICU within each country [1].

At present, data are sparse on the factors associated with EOL decisions in Germany [2]. In Germany, the majority of surgical and interdisciplinary ICUs are managed by anesthesiologists who are also in charge of patient care. Since the status of structural aspects and the relevance of EOL in German ICUs are unknown, we aimed to explore current practice, barriers and opinions on EOL decisions. Due to the increasing importance of EOL-decisions on ICUs and paucity of data, the working group "Epidemiology and Ethics", a scientific working group with emphasis on ethics within the Scientific Working Group Intensive Care Medicine (WAKI) of the German Society of Anesthesiology and Intensive Care Medicine (DGAI), has been supported by the DGAI who addressed EOL in ICU as one of their strategic goals in 2013. The hypotheses of the present survey were: 1.) EOL standard operating procedures (SOPs) are not regularly used in ICU's and 2.) There is a discrepancy between the actual (implementation of items) and the desired status (importance of items) on EOL decisions.

\section{Methods}

After the working group had recommended conducting the survey, the methods were discussed in meetings, telephone conferences and emails by the members of the DGAI working group "Epidemiology and Ethics". The literature about EOL in ICU was researched and with help from an epidemiologist this survey was developed for those items identified as most relevant. Questions were phrased according to publications regarding EOL care and guidelines, such as the Surviving Sepsis Campaign (SSC) 2012 guidelines [3]. After endorsement by the DGAI, 97 questions were reduced to 59 items in order to limit the questionnaire time to $15 \mathrm{~min}$. In the qualitative pilot test, all members of the working group considered the questions relevant, all agreed with the questions, and none of the participants found areas lacking. In November 2015, all members of the DGAI and the Association of German Anesthesiologists (BDA) were invited by email $(n=17,044)$ to participate in the online survey via "www.Umfrageonline.com". Only one reminder was sent out before closing on December 23rd, 2015.

\section{Design}

The survey included nine items about the structure of the ICU and 50 items about prognostic scores, reporting of individual patient outcomes, goals of care, patient autonomy, standard operating procedures, quality management, limitations of life-sustaining therapy, nursing aspects and concepts of care for dying patients (Table 1). For each item, participants were asked to state current practice, desired status and importance. Current practice was rated on a modified four-point Likert scale as "yes, always", "often", "sometimes" or "no, never". If "sometimes" or "no, never" was marked, participants were asked to rate whether they considered this as a deficiency, and thus, the desired status. Relevance of an item for the respondents in the implementation domains "sometimes" or "no, never" was estimated as: relevance = "deficiency yes" divided by "deficiency yes and no". Importance was ranked on a four-point Likert-scale ranging from "not important "to "very important". To reduce complexity and for a clearer presentation, we focused on three subgroups regarding the implementation domain: "always/ often", "sometimes" and "never", and on two subgroups regarding the importance: "important" and "not important".

Considering implementation, relevance and resulting implication, we focused on three subgroups:

\begin{tabular}{llll}
\hline & implementation & relevance & implication \\
Category 1: & high & high & sufficient \\
Category 2: & low & low & inessential \\
Category 3: & low & high & unsatisfactory \\
\hline
\end{tabular}

\section{Results}

Eight-hundred twenty-one anesthesiologists $(4.8 \%$ of 17,044 DGAI or BDA member email adresses) responded. The mailing list classified 870 heads of anesthesiology departments. There are no data available how many of these departments run ICUs. After the first email reminder, there was only minimal increase in responses. Thus, no further reminders were sent out. Only completed surveys $(n=541)$ were included in the analysis. Out of the 541 responders, 417 stated the name of their department, resulting in 305 reponders from different departments. Thus, the response rate reflects more than $1 / 3$ of anesthesiology departments in Germany. Almost all questions were answered by the participants, thus, demonstrating the ability of the questionnaire to distinguish between different respondents. 
Table 1 Questions (Q 1-50) regarding EOL and Categories (C 1-3) Prognosis and outcome (Q 1-7)

Q1-3 Do you use scores for estimation of prognosis, such as SAPS II or SOFA, to estimate a patient's individual prognosis? C2

Q1 In general? C2

Q2 With ICU stay <24 h? C2

Q3 With ICU stay $>24$ h? C2

Q4 Do you receive outcome data regarding long-term survival after hospital discharge? C3

Q5 Do you receive outcome data from patients discharged to other hospitals or rehabilitation centers? C3

Q6 Do you receive outcome data from patients discharged home? C3

Q7 Do you use outcome data from your hospital for your decisions? C3

Goals of care (curative versus palliative) (Q 8-18)

Q8 Do you use principles of palliative care? C1

Q9 Do you address goals of care within $72 \mathrm{~h}$ of ICU admission? C1

Q10 Do you discuss goals of care and prognosis with patients and families? C1

Q11 Do you document the items and results of these conversations with patients? C1

Q12 Do you document the items and results of these conversations with relatives? $\mathrm{C} 1$

Q13 Do you discuss indications in an interdisciplinary manner? C1

Q14 Do you discuss whether goals are achievable? C1

Q15 Do you discuss ineffective therapy? C1

Q16 Do you establish feasible and realistic treatment goals? C1

Q17 Do you discuss whether a desirable quality of survival is achievable? C1

Q18 Do you decide on and document to allow natural death (AND)? C1

Patient autonomy (Q 19-26)

Q19 Do you document the assumed consent of the patient? C1

Q20 Do you document conversations with relatives regarding the assumed consent of the patient? C1

Q21 Do you document conversations with the patients regarding their priorities regarding their way of life, their perceptions of quality of live, and their wishes for the future? C1

Q22 Do you prepare adequate advanced health care directives (AHDC) which are accepted by all involved parties in case of ICU care and can be applied directly? C3

Q23 Do you have guidelines for dealing with delicate wishes of patients? C3

Q24 Do you have an ethics committee? C1

Q25 Do you perform ethics councils? C3

Q26 Do you perform interdisciplinary ethics case reviews? C3

Standard operating procedures (SOPs), quality management (Q 27-29)

Q27 Do you have SOPs for psychosocial problems? C3

Q28 Do you have SOPs for spiritual problems? C3

Q29 Do you have a room for taking farewell? C1
Table 1 Questions (Q 1-50) regarding EOL and Categories (C 1-3) (Continued)

Which changes in goals of care do you execute in these instances? (Q 30-37)

Q30-31 In case of further deterioration of defined organ functions in patients with advanced severe underlying disease or relevant functional impairments with primarily equal treatment goals of a potentially reversible acute process (i.e., treatment of pneumonia, pulmonary embolism, mass reduction surgery of tumor), do you perform:

Q30 Continuation and escalation of therapy with all consecutive life-sustaining activities? C1

Q31 Change in goals of care, adjustment of therapy to the new goals, usually by limitations of care? C1

Q32 DNR (Do Not Resuscitate) C1

Q33 DNE (Do Not Escalate) C1

Q34 RID (Re-evaluate Indication and De-escalate) C3

Q35 CTC (Comfort Terminal Care) C3

Q36 Is the decision to changing goals of care authorized by a physician, communicated during handover of duty, checked daily and documented in the patient chart / patient data management system? C1

Q37 Do you have a checklist" items for intensive care medicine for individual changes in treatment goals"? C3

Nursing aspects (Q 38-40)

Q38 Do you integrate nurses' opinions? C1

Q39 Do you implement palliative care concepts, such as adaption of oral care, noise, light, basal stimulation? C1

Q40 Is the nursing staff educated in palliative care? C3

Concepts of care in the terminal phase (Q 40-50)

Q41 Do you use SOPs for EOL? C3

Q42 Do you do an appraisal of the initial situation? C1

Q43 Is there care for others, such as relatives or the primary care physician, once the patient has died? C3

Q44 Do you use the Liverpool pathway of care? C2

Q45 Do you administer diaries of patients? C2

Q46 Do you administer diaries of relatives? C2

Q47 Do you involve relatives to attend when death occurs? C1

Q48 Do you offer attendance by psychologists, social workers, spiritual care? C1

Q49 Do you consider intercultural aspects? C1

Q50 Are visiting hours handled flexible according to the needs of the relatives? C1

Sufficient Category 1 reflects high implementation and high relevance, inessential Category 2 low and low, and unsatisfactory Category 3 low and high, respectively

\section{Structural items}

There was a higher likelihood of physicians working in university hospitals to participate in the survey: $19 \%$ of respondents, but only $8 \%$ of the ICU's involved were from university hospitals. Thirty-two percent of respondents worked in maximal care hospitals (level 1), $29 \%$ in priority care hospitals (level 2), and $39 \%$ in basic and regular care hospitals (level 3). Predominantly, experienced physicians participated in 
this inquiry: $12 \%$ were department heads, $8 \%$ ICU directors, $32 \%$ anesthesia and intensive care specialists and $16 \%$ residents. The participants had experience in intensive care medicine less than 5 years in $26 \%$, between 5 and 10 years in $26 \%$ and more than 10 years in $48 \%$.

Regarding the institutions the respondents worked at, $53 \%$ were public or community hospitals, $17 \%$ were privately owned, $24 \%$ pertained to churches and $6 \%$ to common welfare organizations. The characteristics of the involved ICU's are presented in Table 2. Since multiple responses were possible regarding treated patients, the sum of treated patients exceeds $100 \%$.

\section{Current practice and estimation of relevance}

Only four items reached $\geq 90 \%$ agreement as being performed "yes, always" or "mostly" (questions (Q) Q10, Q12, Q20, Q50). Twenty-nine items were rated by $\geq 90 \%$ of respondents as "very" or "more important". There was a profound discrepancy between current practice and importance (Table 3, Figs. 1, 2 and 3, Additional files 1, 2, 3, 4, 5, 6, 7, 8, 9 and 10: Figures S1-S10).

Category 1 (sufficient): Items were of high importance with a high degree of implementation that were judged as relevant by those who didn't have them $(n=28)$. (Items, Q 8-21, 24, 29-33, 36, 38, 39, 42, 47-50, Fig. 1, Additional files 1, 2, 3, 4, 5 and 6: Figures S1-S6).

Category 2 (inessential): Items were of minor importance with a lesser degree of implementation that were not considered a deficiency by those who didn't have them $(n=6)$. (Items, Q 1-3, 44-46, Fig. 2, Additional file 7: Figure S7).

Category 3 (unsatisfactory): Items were of high importance that were rarely implemented but were considered to be highly relevant ( $n=16)$. (Items, Q 4-7, 22, 23, 25-28, 34, 35, 37, 40, 41, 43, Fig. 3, Additional files 8, 9 and 10: Figures S8-S10).

Of 44 items considered to be important, 24 were attributed to sufficient Category 1 (Table 3, Fig. 1, Additional files 1, 2, 3, 4, 5 and 6: Figures S1-S6) and six to unsatisfactory Category 3 (Table 3, Fig. 3, Additional files 8, 9 and 10: Figures S8-S10). Items were marked as "very" or "more important" by $>90 \%$ of respondents.

Mean percentages of responses in the three categories are presented in Table 3 regarding implementation (always / often), importance (important), implementation discrepancy (difference between percentage values regarding "importance" and "status of implementation") and relevance ("deficiency yes" divided by "deficiency yes and no" in the implementation domains "sometimes" or "no, never"). The highest level of importance was found for sufficient Category 1 items which lacked implementation in $1 / 4$ of respondents. Unsatisfactory Category 3 items were ranked less important than sufficient Category 1 items but still reached high importance levels. There was a substantial implementation discrepancy characterizing those items with the greatest need for a change in practice, i.e., unsatisfactory Category 3 items. The relevance was profoundly lower than the importance in all categories.

The unsatisfactory Category 3 items characterizing the most urgent need for improvement referred to patient outcome data: Q 4-7 (Fig. 3), preparation of health care directives and interdisciplinary discussion: Q 22, 23, 25, 26 (Additional file 8: Figure S8), development of SOPs: Q 27, 28 , the implementation of practical instructions: Q 34, 35, 37 (Additional files 9 and 10: Figures S9 and S10) and the inclusion of nursing staff and families in the process: Q 40, 41, 43 (Additional file 10: Figure S10).

\section{Discussion}

The present survey revealed a discrepancy between current practice of EOL and perceived importance and lack of particular feedback, education, and tools. This was especially important for outcome data and advanced care planning. For the first time, in greater than $1 / 3$ of anesthesiology departments running ICUs in Germany, a survey revealed a valuable insight in current practice,

Table 2 Characteristics of involved ICU's from 541 responses

\begin{tabular}{|c|c|c|c|c|c|c|c|}
\hline ICU type & Surgical & Mixed & Medical & & & & \\
\hline (\%) & 31 & 68 & 1 & & & & \\
\hline Treated patients & Cardiac surgery & Cardiology & Neurosurgery & Neurology & Trauma & & \\
\hline (\%) & 7 & 5 & 14 & 7 & 23 & & \\
\hline Treated patients & Otorhinolaryngology & Gynecology & Urology & Pediatrics & Pediatric surgery & & \\
\hline (\%) & 9 & 17 & 15 & 1 & 2 & & \\
\hline Number of ICU beds ${ }^{2}$ & $\leq 5$ & $<10$ & $11-15$ & $16-20$ & $21-30$ & $31-40$ & $>40$ \\
\hline (\%) & 1 & 26 & 28 & 21 & 13 & 6 & 5 \\
\hline Number of ventilator beds ${ }^{2}$ & $\leq 5$ & $6-10$ & $11-15$ & $16-20$ & $21-30$ & $31-40$ & $>40$ \\
\hline (\%) & 16 & 30 & 24 & 14 & 7 & 4 & 5 \\
\hline Patients annually & $\leq 500$ & $501-1000$ & $1001-1500$ & $1501-2000$ & $>2000$ & & \\
\hline (\%) & 12 & 30 & 23 & 15 & 21 & & \\
\hline
\end{tabular}


Table 3 Differentiation of current practice, importance, implementation discrepancy and relevance according to categories

\begin{tabular}{lllll}
\hline Category & $\begin{array}{l}\text { Status of implementation (always / often) } \\
(\text { mean } \pm \text { SD) }\end{array}$ & $\begin{array}{l}\text { Importance (important) } \\
(\text { mean } \pm \text { SD) }\end{array}$ & $\begin{array}{l}\text { Implementation discrepancy } \\
\text { (mean } \pm \text { SD) }\end{array}$ & $\begin{array}{l}\text { Relevance } \\
\text { (mean } \pm \text { SD) }\end{array}$ \\
\hline $\begin{array}{l}\text { Category 1 (\%) } \\
n=28\end{array}$ & $71 \pm 14$ & $95 \pm 4$ & $24 \pm 13$ & $75 \pm 16$ \\
$\begin{array}{l}\text { Category 2 (\%) } \\
n=6\end{array}$ & $21 \pm 23$ & $38 \pm 9$ & $17 \pm 19$ & $30 \pm 7$ \\
$\begin{array}{l}\text { Category 3 (\%) } \\
n=16\end{array}$ & $17 \pm 15$ & $79 \pm 14$ & $62 \pm 15$ & $66 \pm 15$ \\
\hline
\end{tabular}

Percentage of responses in regards to: status of implementation (always / often), importance (important), implementation discrepancy (difference between percentage values regarding "importance" and "status of implementation always / often") and relevance ("deficiency yes" divided by "deficiency yes and no" in the implementation domains "sometimes" or "no, never")

barriers, perceived importance, relevance and deficits of EOL decisions in surgical and interdisciplinary ICUs, which may serve for improvement in EOL. Perhaps, just the most engaged anesthesiologists in EOL have responded because many anesthesiologists do not work in critical care. Thus, their response highlights very informatively where to focus to reduce deficits in German ICUs.
First of all, we wanted to know whether prognostic scores play a role in EOL decisions in German ICUs. SAPS II is regularly recorded on a daily basis in Germany for calculation of diagnosis related groups (DRG's) and reimbursement. Therefore, we expected that SAPS II might be used for estimation of prognosis, also, which might have influence on EOL decision

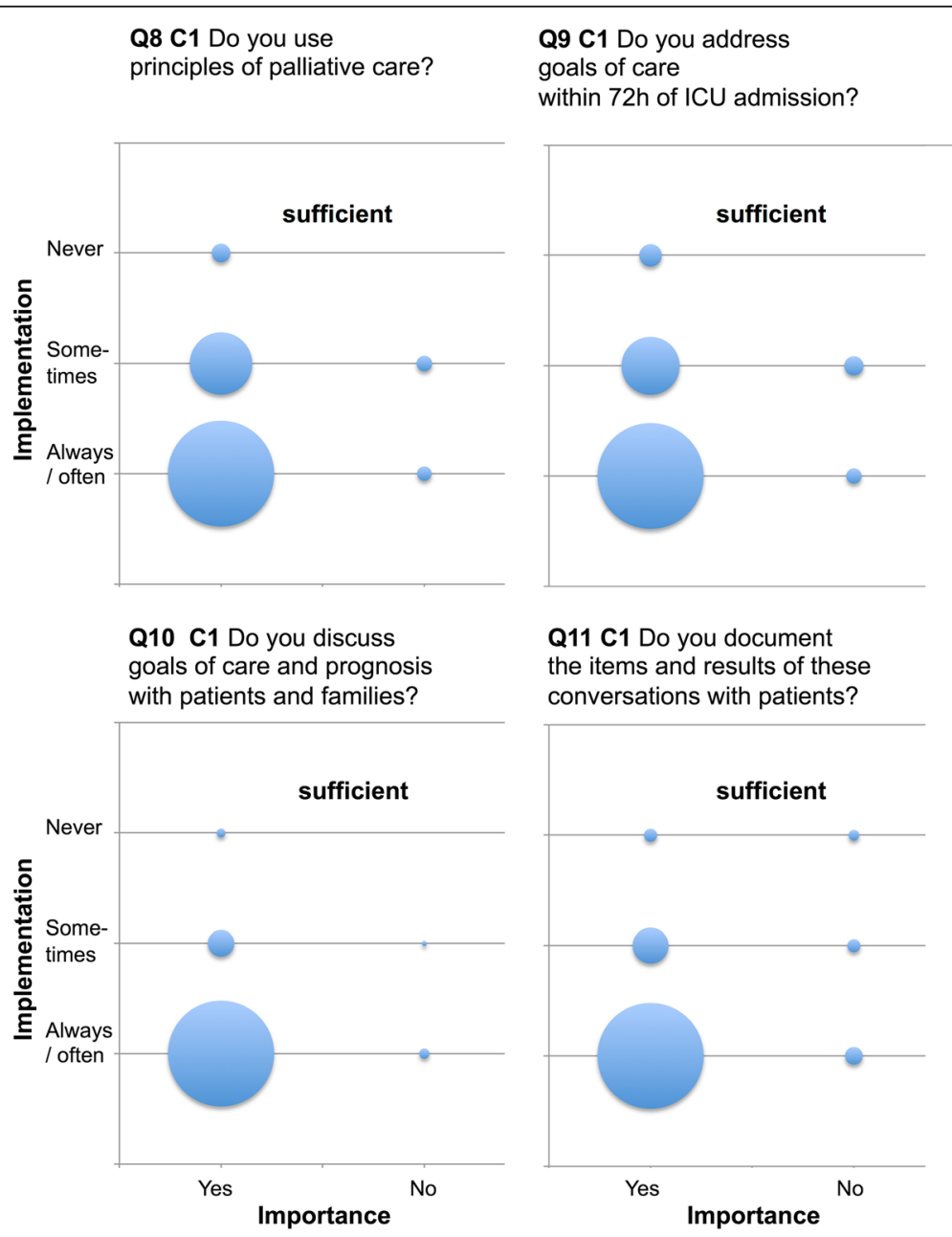

Fig. 1 EOL items Q8-11 of high implementation and high relevance (sufficient Category 1). Data are presented as "blob-o-grams" were the number of respondents in each category is represented by a circle whose area is proportional to the number. Importance (x-axis) and status of implementation (y-axis) are rated on modified Likert scales. Q $=$ Question. C1 = sufficient Category 1 
Q44 C2 Do you use

the Liverpool pathway of care?

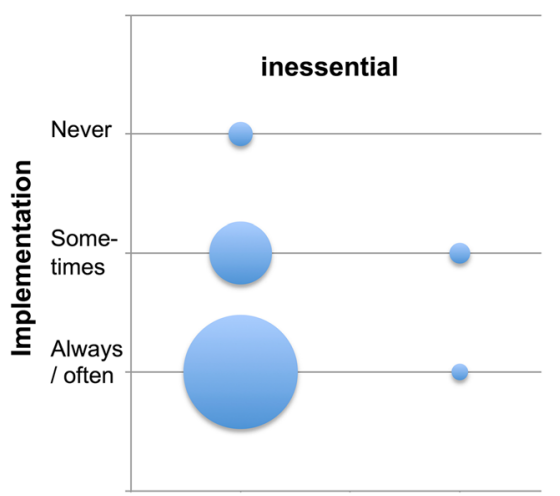

Q45 C2 Do you administer diaries of patients?

Q46 C2 Do you administer diaries of relatives?

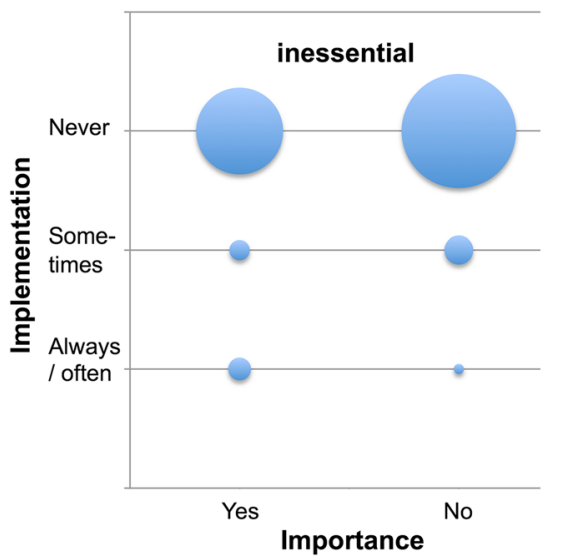

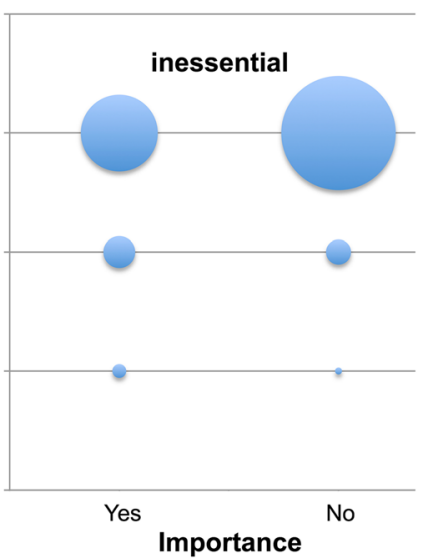

Fig. 2 EOL items Q44-46 of low implementation and low relevance (inessential Category 2). Data are presented as "blob-o-grams" were the number of respondents in each category is represented by a circle whose area is proportional to the number. Importance (x-axis) and status of implementation (y-axis) are rated on modified Likert scales. Q = Question. C2 = inessential Category 2

making. The results of the present survey do not corroborate this hypothesis. Although SAPS II [4] (Simplified Acute Physiology Score) or SOFA [5] (Sequential Organ Failure Assessment) scores were originally developed for estimation of prognosis, they were hardly used for this purpose in the present survey and categorized as inessential Category 2 (Additional file 7: Figure S7). The prognostic performance of SAPS II is poor [6], better with SAPS 3 [7] and SOFA [5], all predict outcome for a given subgroup of patients, but fail for a single patient. Due to limited ICU resources, physicians seek prediction tools to facilitate allocation of ICU beds to patients which might benefit best. In this context, an initial refusal and final triage score provided objective data for rejecting patients that will die even if admitted to the ICU and survive if refused [8]. The mortality benefit regarding ICU admission appeared greater for the elderly [9].
In absence of adequate prediction models of outcome, the majority of respondents judged feedback on outcome data as very important for individual decision making (Q 4-7, attributed to unsatisfactory Category 3, Fig. 3). A considerable variability between hospitals and physicians in terms of EOL care in ICUs is due, in large part, to the lack of compelling evidence or professional consensus for specific approaches that ensure patients of receiving the care they would want if fully informed about their prognosis and likely outcomes [10]. EOL decisions might be improved by establishing interdisciplinary rounds, advanced health care planning, and structured feedback on outcome data.

Questions Q8-18 regarding curative vs. palliative goals of care were answered to be in the sufficient Category 1 (Fig. 1, Additional files 1 and 2: Figures $\mathrm{S} 1$ and S2). However, the answers to these goals of care bear a high 


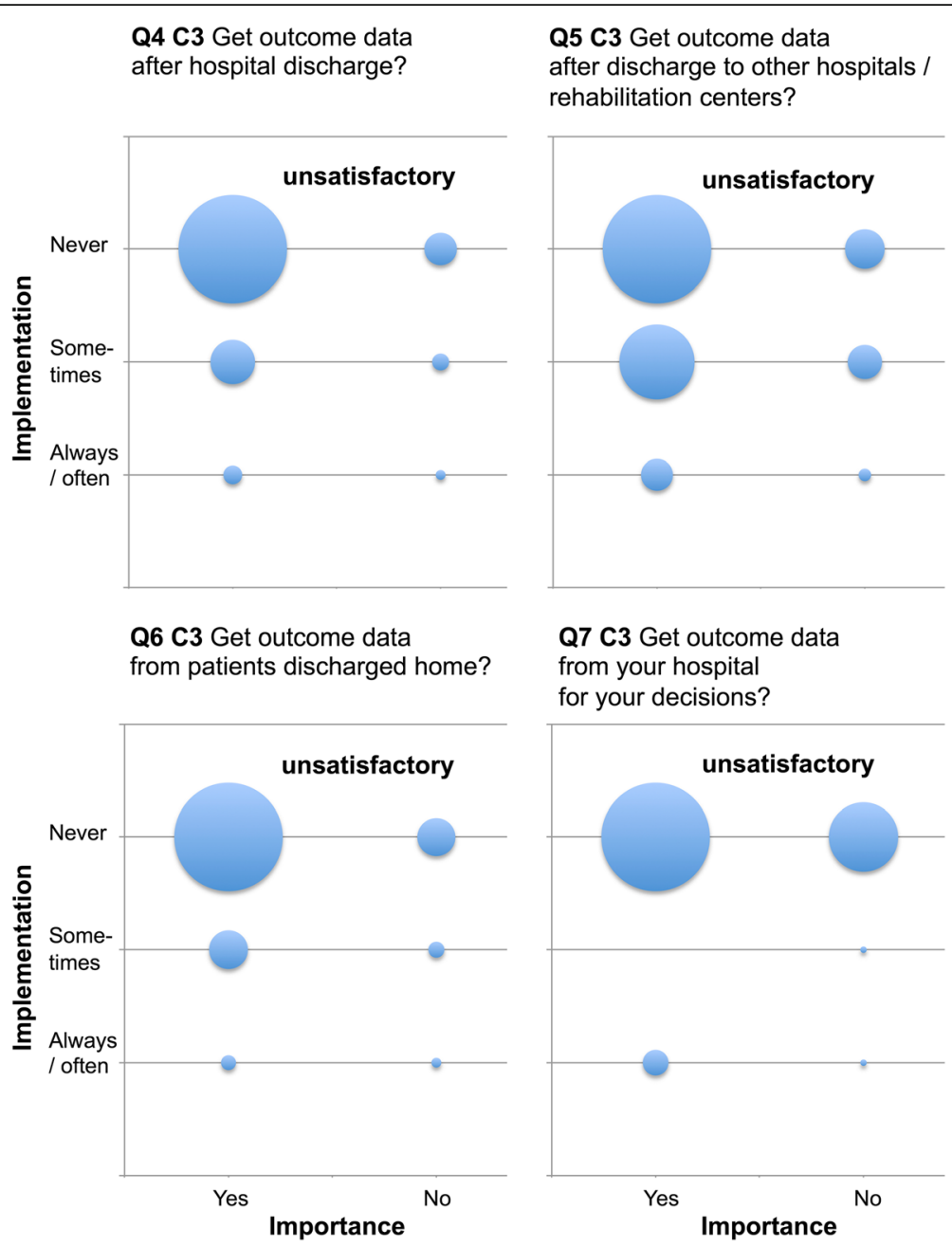

Fig. 3 EOL items Q4 - Q7 of high importance that are rarely implemented but are considered to be highly relevant (unsatisfactory Category 3). Data are presented as "blob-o-grams" were the number of respondents in each category is represented by a circle whose area is proportional to the number. Importance ( $\mathrm{x}$-axis) and status of implementation (y-axis) are rated on modified Likert scales. Q = Question. C3 = unsatisfactory Category 3

risk of societally acceptable responses. The issue of "setting goals of care" (Q9 and Q10) has been addressed by the Surviving Sepsis Campaign (SSC) 2012 guidelines [3] and reiterated in the 2016 guidelines [11]. Initiatives to enhance care in the ICU highlight the importance of incorporating goals of care together with the prognosis into treatment plans [12]. It has been reported that less than half of the ICU physicians felt comfortable in having EOL discussions with patients' families [13]. Therefore, even well-intended clinicians may miss valuable opportunities to address and clarify families' misunderstandings and concerns regarding goals of care at EOL [14]. Moreover, while the estimations of risks and prognosis may change during hospital stay, patients and families often are unable to move beyond the very first prognostic statements. We emphasize that these skills regarding curative vs. palliative goals of care should be regarded as essential and trained accordingly.
The participants identified SOPs dealing with psychosocial (Q27) and spiritual (Q28) problems as an issue of unsatisfactory Category 3 (Additional file 9: Figure S9). In Germany, an approach to these aspects has been published [15], specifying ethical principles, legal basics, patient autonomy, decision making and implementation regarding limitation of care and change in goals of care, unity of patient and family, cultural and religious influences as well as conflicts and burnout in the caregiving team. In Canada, a series of guidelines address withdrawal, distress and discontinuation [16]. There is a critical need to reframe EOL care planning, not prioritizing life extension over good death [17]. Thus, tools are already available to enable a shift from unsatisfactory Category 3 to sufficient Category 1.

Another deficiency identified was the lack of support regarding "changes in goals of care"(Q34, 35, 37), RID 
(Re-evaluate Indication and De-escalate) and CTC (Comfort Terminal Care) (Additional files 9 and 10: Figures S9 and S10). Checklists may be helpful, and guidelines for changes in goals of care [18] utilizing DNR (Do Not Resuscitate), DNE (Do Not Escalate), RID and CTC have recently been published, reevaluating, documenting and changing on demand goals of care on a daily basis. However, although acuity of illness and organ dysfunction consistently predicted mortality in critically ill patient populations, only elements of the past medical history were positively associated with a DNR order [19]. The WELPICUS study has achieved world-wide consensus on key EOL issues and terminology [20]. However, EOL decisions are very variable between regions, countries, individual ICU's and individual clinicians in the same ICU [21, 22], often driven by the views of individual physicians and hospital norms [10]. Instead of "no escalation of treatment", a "time-limited trial" of life support has been advocated [23]. In practice, withholding preceded or accompanied withdrawal in $>90 \%$ of patients [22], and was more likely to occur during on-call hours [24]. It is noteworthy that withholding and withdrawal reflect the limitation of life sustaining treatments, but it is essential in the communication with the team, the patient and the relatives that a change in goals of care does not mean the cessation of medical care [25].

Another area of need in the present survey was EOL education (Q40, Additional file 10: Figure S10). The World Health Organization defines palliative care as 'an approach that improves the quality of life of patients and their families' [26]. In everyday practice, adoption of the 'ABCDs' of EOL critical care is applicable: Attitudes, Behaviours, Compassion and Dialogue [27]. Presently, between $10 \%$ and $20 \%$ of the population at large now die in the ICU underlining the importance of EOL care to everyday practice and training [25], being extended to EOL orders (Q41) for continuing care after death for relatives (Q43) (Additional file 10: Figure S10). Many clinicians and families equate withholding or withdrawing as giving up [17]. Communication and intervention withdrawal practice guidelines that highlight EOL care as part of, rather than separate from, critical care and education [28] are available and may be crucial in supporting ICU teams to help make good death more accessible [17].

Unfortunately, only a minority of DGAI and BDA members participated in the survey. Thus, the results are not representative. Moreover, due to the voluntary participation, it must be appropriately considered that the most unsatisfied colleagues may have responded willingly, or just the most engaged in EOL. Many anesthesiologists do not work in ICUs and hospitals. Thus, we cannot state how many respondents would be eligible and representative for an EOL survey. It remains unclear, whether EOL is regarded not important or not as a problem. Also, due to the voluntary participation, the distribution of health care providers of respondents was not a representative selection. In 2015, in Germany, 38\% of hospitals running ICUs were allocated to public or community hospitals (vs. 53\% in present survey), 21\% (vs. $17 \%$ ) to privately owned, and $41 \%$ (vs. $30 \%$ ) to churches and to common welfare organizations [29]. 1177 out of 1956 hospitals stated ICU beds, and 416 intensive care medicine departments [29]. No representative data were available regarding the percentage of hospitals and ICUs in Germany treating $\leq 500$ up to $>2000$ patients / year as given in Table 2. To our surprise, some colleagues reported that they were not permitted to participate by their hospital chief executive officers (CEO's) for the fear of disclosing sensitive information. Physicians informed their CEO's and data security engineers, and some were not allowed to participate due to safety concerns with the online survey via "www.Umfrageonline.com", because this evaluation might not be anonymised as confirmed. This barrier to scientific investigations driven by economic competition is worrisome and could likely increase in the future.

The present survey was only addressed to anesthesiologists, and therefore, the results cannot be generalized to other specialties, professions, or persons affected by EOL decisions, such as nurses, palliative care experts, or families. It is appreciated that surveys regarding EOL care might show different results for different participating subpopulations [10, 21, 22].

\section{Conclusions}

The present survey reveals an urgent need for improvement in EOL practice in German ICUs. Improvement might be achieved by focusing on desirable quality of life, advanced care planning, continuing EOL education and feedback on outcome data. A shift from unsatisfactory Category 3 to sufficient Category 1 may be enabled by generating awareness regarding deficits in EOL care and deliver already available tools via specialist societies, such as the German Society of Anesthesiology and Intensive Care Medicine (DGAI). To improve EOL care in ICUs run by anesthesiologists in Germany, therapeutic indications have to be clean-cut, followed by decision making and implementation by the main players, the physicians and nurses, the patients, their legal representatives and families.

\section{Additional files}

Additional file 1: Figure S1. EOL items Q12-15 of high implementation and high relevance (sufficient Category 1). Data are presented as "blob-ograms" were the number of respondents in each category is represented by a circle whose area is proportional to the number. Importance ( $x$-axis) and status of implementation (y-axis) are rated on modified Likert scales.

$\mathrm{Q}=$ Question. C1 = sufficient Category 1. (JPEG $1380 \mathrm{~kb}$ )

Additional file 2: Figure S2. EOL items Q16-19 of sufficient Category 1. Data are presented as "blob-o-grams" were the number of respondents in each category is represented by a circle whose area is proportional to the number. Importance ( $x$-axis) and status of implementation (y-axis) are 
rated on modified Likert scales. $\mathrm{Q}=$ Question. $\mathrm{C} 1$ = sufficient Category 1. (JPEG $1461 \mathrm{~kb}$ )

Additional file 3: Figure S3. EOL items Q20, 21, 24, 29 of sufficient Category 1. Data are presented as "blob-o-grams" were the number of respondents in each category is represented by a circle whose area is proportional to the number. Importance ( $x$-axis) and status of implementation (y-axis) are rated on modified Likert scales. $\mathrm{Q}=$ Question. C1 = sufficient Category 1. (JPEG $1446 \mathrm{~kb}$ )

Additional file 4: Figure S4. EOL items Q30-33 of sufficient Category 1. Data are presented as "blob-o-grams" were the number of respondents in each category is represented by a circle whose area is proportional to the number. Importance ( $x$-axis) and status of implementation ( $y$-axis) are rated on modified Likert scales. $\mathrm{Q}=$ Question. C1 = sufficient Category 1. (JPEG 1482 kb)

Additional file 5: Figure S5. EOL items Q36, 38, 39, 42 of sufficient Category 1. Data are presented as "blob-o-grams" were the number of respondents in each category is represented by a circle whose area is proportional to the number. Importance $(x$-axis) and status of implementation (y-axis) are rated on modified Likert scales. $Q=$ Question. $\mathrm{C1}=$ sufficient Category 1. (JPEG $1335 \mathrm{~kb}$ )

Additional file 6: Figure S6. EOL items Q47-50 of sufficient Category 1. Data are presented as "blob-o-grams" were the number of respondents in each category is represented by a circle whose area is proportional to the number. Importance (x-axis) and status of implementation (y-axis) are rated on modified Likert scales. $Q=$ Question. $C 1=$ sufficient Category 1 . (JPEG $1354 \mathrm{~kb}$ )

Additional file 7: Figure S7. EOL items Q1-3 of low implementation and low relevance (inessential Category 2). Data are presented as "blob-ograms" were the number of respondents in each category is represented by a circle whose area is proportional to the number. Importance ( $x$-axis) and status of implementation (y-axis) are rated on modified Likert scales. $\mathrm{Q}=$ Question. C2 = inessential Category 2. (JPEG $1203 \mathrm{~kb}$ )

Additional file 8: Figure S8. $E O L$ items Q22, 23, 25, 26 of high importance that are rarely implemented but are considered to be highly relevant (unsatisfactory Category 3). Data are presented as "blob-ograms" were the number of respondents in each category is represented by a circle whose area is proportional to the number. Importance ( $x$-axis) and status of implementation (y-axis) are rated on modified Likert scales. $\mathrm{Q}=$ Question. C3 = unsatisfactory Category 3. (JPEG $1486 \mathrm{~kb}$ )

Additional file 9: Figure S9. EOL items Q27, 28, 34, 35 of unsatisfactory Category 3. Data are presented as "blob-o-grams" were the number of respondents in each category is represented by a circle whose area is proportional to the number. Importance ( $x$-axis) and status of implementation (y-axis) are rated on modified Likert scales. $Q=$ Question. $\mathrm{C} 3=$ unsatisfactory Category 3. (JPEG $1452 \mathrm{~kb}$ )

Additional file 10: Figure S10. EOL items Q37, 40, 41, 43 of unsatisfactory Category 3. Data are presented as "blob-o-grams" were the number of respondents in each category is represented by a circle whose area is proportional to the number. Importance (x-axis) and status of implementation (y-axis) are rated on modified Likert scales. $\mathrm{Q}=$ Question. C3 = unsatisfactory Category 3. (JPEG 1448 kb)

\section{Abbreviations}

ABCDs: Attitudes behaviours compassion and dialogue; AHDC: advanced health care directives; AND: allow natural death; BDA: Association of German anesthesiologists; CEO's: chief executive officer; CTC: Comfort terminal care; DGAl: German society of anesthesiology and intensive care medicine; DNE: Do not escalate; DNR: Do not resuscitate; DRG: diagnosis related groups; EOL: endof-life; ICU: Intensive care units; n: number; $n$. a.: status of implementation given without estimation of importance; Q: question; RID: Re-evaluate indication and De-escalate; SAPS II: Simplified acute physiology score II; SD: standard deviation; SOFA: Sequential organ failure assessment; SOPs: standard operating procedures

\section{Acknowledgements}

We acknowledge Mrs. Karen Schneider, Department of Anesthesiology, Intensive Care Medicine and Pain Medicine, Saarland University Medical Center, Homburg/ Saar, Germany, for her professional help as a native speaker in finalizing this manuscript.

\section{Funding}

None.

\section{Availability of data and materials}

The raw datasets upon which the analyses and summary statistics in this article are based are available from the corresponding author on reasonable request in anonymised form.

\section{Authors's contributions}

$F B, T B, A B, H G, D H, C P, F P, A T$, and $M W$ conceived the study. FB, TB, AB, HG, $\mathrm{DH}, \mathrm{CP}, \mathrm{FP}, \mathrm{AT}$, and $\mathrm{MW}$ considered the questions relevant in the qualitative pilot test, and none found areas lacking. AT, DH and MW extracted and analyzed the data. MT was involved in the discussion with the literature. $\mathrm{DH}, \mathrm{AM}$ and $\mathrm{MW}$ interpreted the results and drafted the manuscript. All of the authors revised the manuscript critically for important intellectual content, approved the final version to be published and agreed to act as guarantors of the work.

\section{Ethics approval and consent to participate}

For the present survey, a formal ethcis approval was not required: in Germany, the provincial medical associations regularly waive the need for ethics approval regarding voluntary surveys without use of personal data and with adequate anonymisation (see $\S 15$ section 1 code of medical ethics of the Medical Association of Mecklenburg-Vorpommern (http:/www.aek-mv.de/upload/file/presse/ Berufsordnung\%205_\%20\%2B\%206_\%20Änderung.pdf; https://ethik.med.unirostock.de/antragsstellung/forschungsvorhaben/) as well as of the Central Ethical Committee of the Medical Association of North Rhine (https://www.aekno.de/ page.asp?pagelD=124; https:/www.aekno.de/page.asp?pagelD=5257). Thus, the DGAI also supported the survey without need for formal ethics approval.

\section{Consent for publication}

Not applicable.

\section{Competing interests}

The authors declare that they have no competing interests.

\section{Publisher's Note}

Springer Nature remains neutral with regard to jurisdictional claims in published maps and institutional affiliations.

\section{Author details}

${ }^{1}$ Clinic of Anaesthesiology, University Hospital Medical School, Alber-Einstein-Allee 23, $89081 \mathrm{Ulm}$, Germany. ${ }^{2}$ Department of Anesthesiology and Critical Care Medicine, Tettnang Hospital, Tettnang, Germany. ${ }^{3}$ Institute of Clinical Economics, Health Care Research at the Hospital of General and Visceral Surgery University Hospital UIm, UIm, Germany. ${ }^{4}$ Department of Anaesthesia, University of Regensburg, Regensburg, Germany. ${ }^{5}$ Palliative Care Einheit, Anästhesie, operative Intensivmedizin, Schmerztherapie, Raphaelsklinik GmbH, Akademisches Lehrkrankenhaus der Westfälischen Wilhelms-Universität Münster, Münster, Germany. ${ }^{6}$ Klinik für Anästhesie, operative Intensivmedizin und spezielle Schmerztherapie, Klinikum Heidenheim, Heidenheim, Germany. ${ }^{7}$ Department of Anesthesiology, Intensive Care Medicine and Pain Medicine, Saarland University Medical Center, Homburg/Saar, Germany. ${ }^{8}$ Department of Anesthesiology and Intensive Care Medicine, University Hospital Bonn, Bonn, Germany. ${ }^{9}$ Klinik für Anästhesiologie, Intensiv-, Transfusions-, Notfallmedizin und Schmerztherapie (AINS), Ev. Krankenhaus Bielefeld, Akad. Lehrkrankenhaus der WWU Münster, Bielefeld, Germany. ${ }^{10}$ Universitätsklinik für Anästhesiologie, op. Intensivmedizin, Rettungsmedizin, Schmerztherapie der Ruhr-Universität Bochum, Klinikum Herford, Herford, Germany.

Received: 6 March 2017 Accepted: 30 June 2017

Published online: 11 July 2017

\section{References}

1. Myburgh J, Abillama F, Chiumello D, Dobb G, Jacobe S, Kleinpell R, Koh Y, Martin C, Michalsen A, Pelosi P, et al. End-of-life care in the intensive care unit: Report from the Task Force of World Federation of Societies of Intensive and Critical Care Medicine. J Crit Care. 2016;34:125-30.

2. Graw JA, Spies CD, Wernecke KD, Braun JP. Managing end-of-life decision making in intensive care medicine-a perspective from Charite Hospital, Germany. PLoS One. 2012;7(10):e46446. 
3. Dellinger RP, Levy MM, Rhodes A, Annane D, Gerlach H, Opal SM, Sevransky JE, Sprung CL, Douglas IS, Jaeschke $R$, et al. Surviving sepsis campaign: international guidelines for management of severe sepsis and septic shock: 2012. Crit Care Med. 2013;41(2):580-637.

4. Le-Gall JR, Lemeshow S, Saulnier F. A new Simplified Acute Physiology Score (SAPS II) based on a European/North American multicenter study. JAMA. 1993; 270(24):2957-63

5. Vincent JL, de Mendonca A, Cantraine F, Moreno R, Takala J, Suter PM, Sprung $\mathrm{CL}$, Colardyn F, Blecher S. Use of the SOFA score to assess the incidence of organ dysfunction/failure in intensive care units: results of a multicenter, prospective study. Working group on "sepsis-related problems" of the European Society of Intensive Care Medicine. Crit Care Med. 1998;26(11):1793-800.

6. Metnitz PG, Moreno RP, Almeida E, Jordan B, Bauer P, Campos RA, lapichino G, Edbrooke D, Capuzzo M, Le Gall JR. SAPS 3-From evaluation of the patient to evaluation of the intensive care unit. Part 1: Objectives, methods and cohort description. Intensive Care Med. 2005;31(10):1336-44.

7. Moreno RP, Metnitz PG, Almeida E, Jordan B, Bauer P, Campos RA, lapichino G, Edbrooke D, Capuzzo M, Le Gall JR. SAPS 3-From evaluation of the patient to evaluation of the intensive care unit. Part 2: Development of a prognostic mode for hospital mortality at ICU admission. Intensive Care Med. 2005;31(10):1345-55.

8. Sprung $\mathrm{CL}$, Baras M, lapichino G, Kesecioglu J, Lippert A, Hargreaves C, Pezzi A, Pirracchio R, Edbrooke DL, Pesenti A, et al. The Eldicus prospective, observational study of triage decision making in European intensive care units: part I-European Intensive Care Admission Triage Scores. Crit Care Med. 2012;40(1):125-31.

9. Sprung CL, Artigas A, Kesecioglu J, Pezzi A, Wiis J, Pirracchio R, Baras M, Edbrooke DL, Pesenti A, Bakker J, et al. The Eldicus prospective, observational study of triage decision making in European intensive care units. Part II: intensive care benefit for the elderly. Crit Care Med. 2012;40(1):132-8.

10. Curtis JR, Engelberg RA, Teno JM. Understanding variability of end-of-life care in the ICU for the elderly. Intensive Care Med. 2016; doi:10.1007/s00134-0001604340-00135.

11. Rhodes A, Evans LE, Alhazzani W, Levy MM, Antonelli M, Ferrer R, Kumar A, Sevransky JE, Sprung CL, Nunnally ME, et al. Surviving Sepsis Campaign: International Guidelines for Management of Sepsis and Septic Shock: 2016. Intensive Care Med. 2017; doi:10.1007/s00134-00017-04683-00136.

12. Nelson JE, Bassett R, Boss RD, Brasel KJ, Campbell ML, Cortez TB, Curtis JR, Lustbader DR, Mulkerin C, Puntillo KA, et al. Models for structuring a clinical initiative to enhance palliative care in the intensive care unit: a report from the IPAL-ICU Project (Improving Palliative Care in the ICU). Crit Care Med. 2010;38(9):1765-72.

13. Phua J, Joynt GM, Nishimura M, Deng Y, Myatra SN, Chan YH, Binh NG, Tan CC, Faruq MO, Arabi YM, et al. Withholding and withdrawal of life-sustaining treatments in intensive care units in Asia. JAMA Intern Med. 2015;175(3):363-71.

14. Curtis JR, Engelberg RA, Wenrich MD, Shannon SE, Treece PD, Rubenfeld GD. Missed opportunities during family conferences about end-of-life care in the intensive care unit. Am J Respir Crit Care Med. 2005;171(8):844-9.

15. Michalsen A, Hartog CS. End-of-Life Care in der Intensivmedizin. Berlin Heidelberg: Springer-Verlag; 2013

16. Downar J, Delaney JW, Hawryluck L, Kenny L. Guidelines for the withdrawal of life-sustaining measures. Intensive Care Med. 2016;42(6):1003-17.

17. Ho A, Tsai DF. Making good death more accessible: end-of-life care in the intensive care unit. Intensive Care Med. 2016;42(8):1258-60.

18. Multidisziplinäre-Arbeitsgruppe: (ARGE) Ethik in Anästhesie und Intensivmedizin der ÖGARI. Therapiezieländerungen auf der Intensivstation Definitionen, Entscheidungsfindung und Dokumentation. Anasthesiol Intensivmed Notfallmed Schmerzther 2013, 48:216-223.

19. Bacchetta MD, Eachempati SR, Fins JJ, Hydo L, Barie PS. Factors influencing DNR decision-making in a surgical ICU. J Am Coll Surg. 2006;202(6):995-1000.

20. Sprung CL, Truog RD, Curtis JR, Joynt GM, Baras M, Michalsen A, Briegel J, Kesecioglu J, Efferen L, De Robertis E, et al. Seeking worldwide professional consensus on the principles of end-of-life care for the critically ill. The Consensus for Worldwide End-of-Life Practice for Patients in Intensive Care Units (WELPICUS) study. Am J Respir Crit Care Med. 2014;190(8):855-66.

21. Mark NM, Rayner SG, Lee NJ, Curtis JR. Global variability in withholding and withdrawal of life-sustaining treatment in the intensive care unit: a systematic review. Intensive Care Med. 2015:41(9):1572-85.

22. Sprung CL, Cohen SL, Sjokvist P, Baras M, Bulow HH, Hovilehto S, Ledoux D, Lippert A, Maia P, Phelan D, et al. End-of-life practices in European intensive care units: the Ethicus Study. JAMA. 2003;290(6):790-7.

23. Curtis JR. Rubenfeld GD: "No escalation of treatment" as a routine strategy for decision-making in the ICU: con. Intensive Care Med. 2014;40(9):1374-6.
24. Collins N, Phelan D, Marsh B, Sprung CL. End-of-life care in the intensive care unit: the Irish Ethicus data. Crit Care Resusc. 2006:8(4):315-20.

25. Connolly C, Miskolci O, Phelan D, Buggy DJ. End-of-life in the ICU: moving from 'withdrawal of care' to a palliative care, patient-centred approach. $\mathrm{Br}$ J Anaesth. 2016;117(2):143-5.

26. World_Health_Organization. In. WHO definition of palliative care. Available from http://www.who.int/cancer/palliative/definition/en/. Accessed 05 Mar 2017.

27. Cook D, Rocker G. Dying with dignity in the intensive care unit. N Engl J Med. 2014;370(26):2506-14.

28. Ho A, Spencer M, McGuire M. When frail individuals or their families request nonindicated interventions: usefulness of the four-box ethical approach. J Am Geriatr Soc. 2015;63(8):1674-8.

29. Statistisches Bundesamt, Wiesbaden 2016. Gesundheit. Grunddaten der Krankenhaeuser 2015. Fachserie 12 Reihe 6.1.1. Accession Number 2120611157004 https://www.destatis.de/DE/Publikationen/Thematisch/Gesundheit/ Krankenhaeuser/GrunddatenKrankenhaeuser2120611157004.pdf?_blob=publicationFile Accessed 05 Mar 2017.

\section{Submit your next manuscript to BioMed Central and we will help you at every step:}

- We accept pre-submission inquiries

- Our selector tool helps you to find the most relevant journal

- We provide round the clock customer support

- Convenient online submission

- Thorough peer review

- Inclusion in PubMed and all major indexing services

- Maximum visibility for your research

Submit your manuscript at www.biomedcentral.com/submit
C) Biomed Central 